\title{
BUKU VISUAL SEBAGAI ENSIKLOPEDIA DAN MEDIA UNTUK PELESTARIAN SEJARAH PENINGGALAN KERAJAAN SINGOSARI
}

\author{
Lutfi Tri Atmaji ${ }^{1}$, Cahyaning U.C Nursyifani ${ }^{2}$ \\ Institut Teknologi Kreatif Bina Nusantara \\ Kota Araya - Malang \\ Email : lutfi.atmaji@binus.ac.id
}

Diterima : 20 Juni 2019. Disetujui : 10 Oktober 2019. Dipublikasikan : 27 Desember 2019

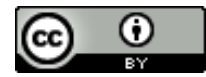

(C2019 - DESKOVI Universitas Maarif Hasyim Latif. Ini adalah artikel dengan akses terbuka di bawah lisensi CC BY 4.0 (https://creativecommons.org/licenses/by/4.0/)

\begin{abstract}
ABSTRAK
Sejarah memiliki peran penting dalam menilai kemajuan peradaban suatu negara. maka penyampaian sejarah dan peninggalan sejarah perlu dilestarikan agar tidak hilang dan dilupakan. Indonesia adalah salah satu negara di Asia yang memiliki sejarah panjang peradaban dengan kerajaan yang pernah berdiri di Indonesia, salah satunya adalah Kerajaan Singosari yang juga merupakan cikal bakal kerajaan Majapahit.Buku Visual Cagar Budaya Purbakala di Kabupaten Malang Mengambil dari fenomena yang ada akan pentingnya pelestarian warisan sejarah suatu bangsa sebagai bagian dari identitas bangsa tersebut. Salah satunya adalah dengan adanya sebuah media informasi dan visual yang menjabarkan secara informatif mengenai warisan cagar budaya purbakala tersebut. Namun mediamedia penunjang tersebut bukanlah karya anak bangsa sendiri melainkan karya peneliti dan arkeolog luar negeri yang justru jauh lebih tertarik dengan sejarah bangsa ini. Maka berangkat dari fenomena tersebut penulis mencoba menyusun sebuah media informasi mengenai wisata situs purbakala di Kabupaten Malang secara visual dan infromatif. Tujuannya agar warisan sejarah sebagai identitas bangsa tidak hilang dan terlupakan juga sebagai media penyalur informasi situs cagar budaya purbakala terhadap wisatawan,peneliti dan kalangan akademisi.
\end{abstract}

Kata kunci: Media, Sejarah, Warisan

\section{ABSTRACT}

History has a significant role in assessing the progress of a nation's civilization. then the delivery of history and historical heritage needs to be preserved so as not to be lost and forgotten. Indonesia is one of the countries in Asia that has a long history of civilization with kingdom that once stood in Indonesia, one of which is the Singosari Kingdom which is also the forerunner of the Majapahit kingdom.The Visual Book Travel Archaeological Heritage of Singosari Kingdom is taking from the phenomena of the importance of preserving the historical heritage of the nation as part of the national identity. One is the presence of a visual media and information outlining the heritage informative about the ancient cultural heritage. But the media is not supporting the work of the nation itself but rather the work of researchers and archaeologists abroad is far more interested in the history of this nation. So departing from this phenomenon the author tries to compile a media of information about the tourist archaeological sites in Malang Regency visually and informally. The goal for the historical legacy as the nation's identity is not lost and forgotten as well as a medium channeling information to the archaeological sites of cultural heritage tourists, researchers and academics.

Keyword: Media, History, Heritage

\section{PENDAHULUAN}

Indonesia merupakan salah satu negara dengan sejarah yang panjang dan cukup tua di Asia. Beberapa kerajaan besar lahir di bumi Nusantara yang merupakan nama dari Indonesia di masa lampau diantaranya Kerajaan Singosari yang merupakan cikal bakal dari kerajaan Majapahit. Kerajaan Singosari atau Singhasari terletak di Kabupaten Malang dan ibukota dari kerajaan Singosari berada di daerah yang sekarang dikenal dengan nama Kecamatan Singosari. Terdapat beberapa peninggalan dari kerajaan Singosari berupa 3 candi, 1 stupa dan sepasang arca raksasa Dwarapala. Menurut humas Dinas Pariwisata dan Kepurbakalaan Djayusman, Kabupaten Malang belum memiliki media ensiklopedi yang merangkum mengenai peninggalan purbakala Kerajaan Singosari sehingga diperlukan sebuah media yang dapat merangkum mengenai semua situs tersebut. Media ensiklopedi tentunya juga berfungsi sebagai sarana pelestarian sejarah budaya dan dapat diterima oleh generasi muda. Ensiklopedi pada umumnya berbentuk buku besar atau bahkan berseri yang berisi banyak tulisan dan terkesan formal. Hal tersebut yang membuat para remaja dan mahasiswa 
kurang tertarik untuk membacanya sehingga perlu dirancang sebuah buku visual dengan konsep yang mampu menarik minat remaja dan mahasiswa untuk membacanya atau menjadikan referensi.

Buku visual yang bertemakan warisan cagar budaya Indonesia sendiri belum cukup banyak, namun dari beberapa buku visual tersebut merupakan hasil karya mancanegara. Hal tersebut membanggakan sekaligus sangat disayangkan karena pihak pengeksploritasi situs bersejarah dan merinci serta memvisualisasikannya dalam bentuk buku visual bukan dari bangsa Indonesia sendiri. Meskipun terdapat beberapa buku yang menjabarkan mengenai sejarah daripada situs purbakala tersebut namun kurang menarik dan dibuat apa adanya. Dari beberapa buku berkonsep visual yang ada dan mengangkat tema mengenai kebudayaan dan peninggalan cagar budaya di Indonesia diantaranya "The Sculpture of Indonesia" dan "Worshiping Siva and Buddha: The Temple Art of East Java Author". Perancangan buku visual sebagai media pelestarian budaya dan ensiklopedi sangat dibutuhkan sebagai media pelestarian sejarah Indonesia khususnya mengenai Kerajaan Singosari dan peninggalannya.

\section{Kriteria Nilai}

Bangunan atau peninggalan cagar budaya purbakala memiliki nilai-nilai yang terkandung di dalamnya yang mencerminkan suatu bangsa sehingga keberadaan akan peninggalan tersebut patut dilestarikan keberadaannya maupun nilai-nilai yang terkandung di dalamnya (Widiyanto, DR. M. Balquni. Perencanaan dan Pengembangan Pariwisata. Bandung). Nilai-nilai yang terdapat di situs cagar budaya purbakala Kabupaten Malang sehingga layak untuk dipromosikan dan dilestarikan adalah:

\section{Nilai Sejarah}

Berdasarkan bukti-bukti arkeologis, beberapa situs dahulu merupakan pusat dari pemerintahan kerajaan Singasari, tempat peribadatan dan monumen atau tetengger. Nilai sejarah mengedepankan pada bukti-bukti penggalian atau arkeologis dan kajian ilmiah yang ada dan membuktikan bahwa di suatu situs dahulunya merupakan sebuah pusat pemerintahan atau kebudayaan suatu peradaban.

2. Nilai Pengetahuan

Nilai pengetahuan memberikan potensi akan informasi yang terjadi di masa lampau melalui peninggalan-peninggalan suatu kerajaan atau sebuah peradaban. Seperti struktural arsitektur suatu bangunan candi atau situs purbakala dapat memberikan informasi mengenai teknologi yang dipergunakan pada masa lalu. Data mengenai artefak memberikan pengetahuan mengenai sistim pengolahan bahan tanah liat dimasa lampau.

3. Nilai Kebudayaan

Artefak-artefak seni dan bangunan-bangunan yang meghasilkan corak-corak yang unik dan khas menjadi sebuah pertumbuhan seni dan dapat berpengaruh pada zaman-zaman berikutnya. Dimana nilai budaya adalah aset yang dapat berpengaruh pada perubahan atau perkembangan suatu kebudayaan atau peradaban bahkan hingga zaman-zaman atau masamasa sesudahnya.

\section{Manfaat Penelitian}

1. Secara teoritis Buku visual ini akan berfungsi sebagai media sarana informasi bagi situs-situs purbakala yang ada di Kabupaten malang sehingga mampu ikut melestarikan sejarah dari kerajaan Singosari.

2. Secara akademis penelitian ini dapat digunakan sebagai bahan kajian tentang perancangan buku visual yang bertema sejarah dan budaya, khususnya mengenai situs cagar budaya purbakala di Kabupaten Malang

3. Media buku visual dapat digunakan sebagai sumber pembelajaran dan kajian tentang sejarah Kerajaan Singosari melalui peninggalannya dan di distribusikan kepada stakeholder yang membutuhkan.

4. Bagi Mahasiswa Desain Komunikasi Visual penelitian ini dapat digunakan sebagai bahan acuan tugas perancangan buku visual.

\section{METODE PENCIPTAAN}

\section{Populasi dan Sampel}

Berdasarkan pertimbangan dari Dinas Kebudayaan dan Pariwisata Kabupaten malang diperoleh gambaran audience yang akan diteliti, yaitu konsumen/orang pada tahap dewasa aktif dengan jarak umur antara 19-35 tahun dan dianggap memiliki potensi besar akan ketertarikan terhadap budaya dan sejarah. Berdasarkan pertimbangan tersebut, maka diperoleh demografi sebagai berikut:

- Usia : 19 - 35 tahun

- Jenis Kelamin : L \& P

- SES : Menengah ke atas

- Pengeluaran : >500.000

- Pendidikan : minimal SMA

- Interest : Bidang sejarah,budaya, dan ilmu pengetahuan

- Geografis : Urban khususnya kota-kota di Jawa Timur

Data demografi yang diperoleh, kemudian dikembangkan dengan perolehan data-data lain menjadi dua jenis, yaitu:

\section{Data Primer}

1. Wawancara kepada Djayusman sebagai Ketua Bidang Usaha, Jasa dan Sarana Wisata Dinas Kebudayaan dan Pariwisata Kabupaten Malang.

2. Wawancara dengan pengurus dan penjaga situs purbakala di masing-masing tempat atau lokasi. 


\section{Data Sekunder}

1. Buku literatur sebagai bahan penunjang penelitian berupa buku mengenai teori pariwisata, komunikasi, perilaku konsumen, undang-undang mengenai cagar wisata, layout, tipografi dan buku rencana kerja Pemerintah Kabupaten Malang.

2. Media massa cetak dan media informasi berbasis internet berupa e-book mengenai materi fotografi, visual dan artikel pendukung lainnya.

3. Observasi dan penelitian lapangan dengan mengunjungi situs-situs cagar budaya purbakala yang berada di Kabupaten malang, yaitu: Candi Singasari, Candi Kidal, Arca Dwarapala, Stupa Sumberawan, dan Candi Jago.

\section{Proses Desain}

Berikut merupakan bagan proses desain :

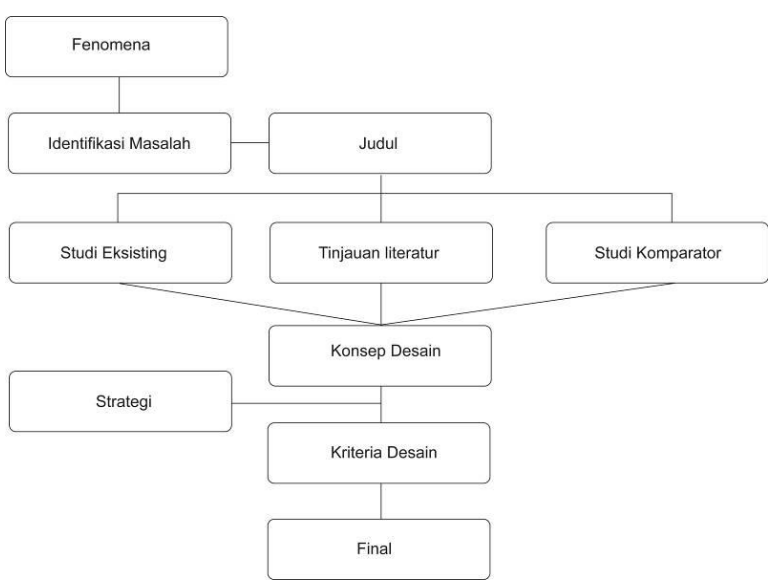

Gambar 1. Proses Desain

1. Identifikasi Masalah merupakan proses awal dalam tahapan perancangan ini untuk mengetahui permasalahan yang ada.

2. Tinjauan Literatur diperoleh sesuai dengan perancangan meliputi tinjauan kepariwisataan, tinjauan promosi dan tinjauan media yang meliputi studi tentang layout dan elemen pembentuknya serta studi fotografi.

3. Studi Eksisting, pembahasan yang dilakukan meliputi komparasi terhadap buku dengan tema sejenis yaitu wisata, budaya dan sejarah dan lebih dispesifikkan dengan sejarah kepurbakalaan.

\section{PEMBAHASAN}

\section{Target Audience}

Target audience yang diteliti adalah remaja hingga dewasa dengan kisaran usia 19-50 tahun. Target audience tersebut dibagi menjadi primer dan sekunder berdasar pada karakteristiknya. Target audience primer adalah mereka yang memiliki peluang besar untuk memanfaatkan buku visual sedangkan Target audience sekunder adalah mereka yang tidak memiliki keterkaitan langsung dengan media maupun konten dalam buku visual wisata purbakala namun tetap memiliki potensi untuk memanfaatkan media buku visual.

\section{Konsep Desain}

Menurut hasil wawancara mengenai konten atau isi buku yang ditampilkan, responden memilih informasi mengenai sejarah situs purbakala, peta interaktif ,serta informasi relief dan ornamen di lokasi situs.

1. USP ( Unique Selling Preposition )

a. Berisi mengenai kajian informasi dan visual tentang cagar budaya purbakala.

b. Mengangkat tema sejarah kepurbakalaan.

c. Visualisasi atau rekonstruksi struktur kepurbakalaan.

d. Pemetaan situs berdasarkan pada era/masanya.

e. Dari Bangsa Indonesia, menjabarkan tentang sejarah Bangsa Indonesia dan untuk Bangsa Indonesia.

\section{Strategi Komunikasi Visual}

Konsumen buku visual ini adalah wisatawan pada umumnya dan akademisi serta peneliti atau mereka yang membutuhkan informasi dan pengetahuan mengenai sejarah kepurbakalaan di kabupaten Malang. Oleh karenanya, tatanan gaya bahasa menggunakan bahasa formal karena pembaca merupakan kalangan usia dewasa.

\section{Keyword}

Keyword dirancang untuk menentukan tema yang akan diaplikasikan pada buku visual.. Gambar diagaram alur keyword dijelaskan pada gambar 2 .

\section{Kriteria Desain}

\section{Gaya Bahasa}

Bahasa yang digunakan dalam perancangan ini adalah bahasa Indonesia Formal, pemilihan gaya bahasa ini mengacu pada tema yang diangkat dari buku visual tersebut yang bersifat pengetahuan.

2. Sistematika Buku

Buku ini berukuran $145 \mathrm{~mm}$ x $200 \mathrm{~mm}$ dengan mempertimbangkan permintaan dari pihak stakeholder serta melihat dari komparator dan kompetitor yaitu buku visual Majapahit Terracotta yang memiliki ukuran serupa. 


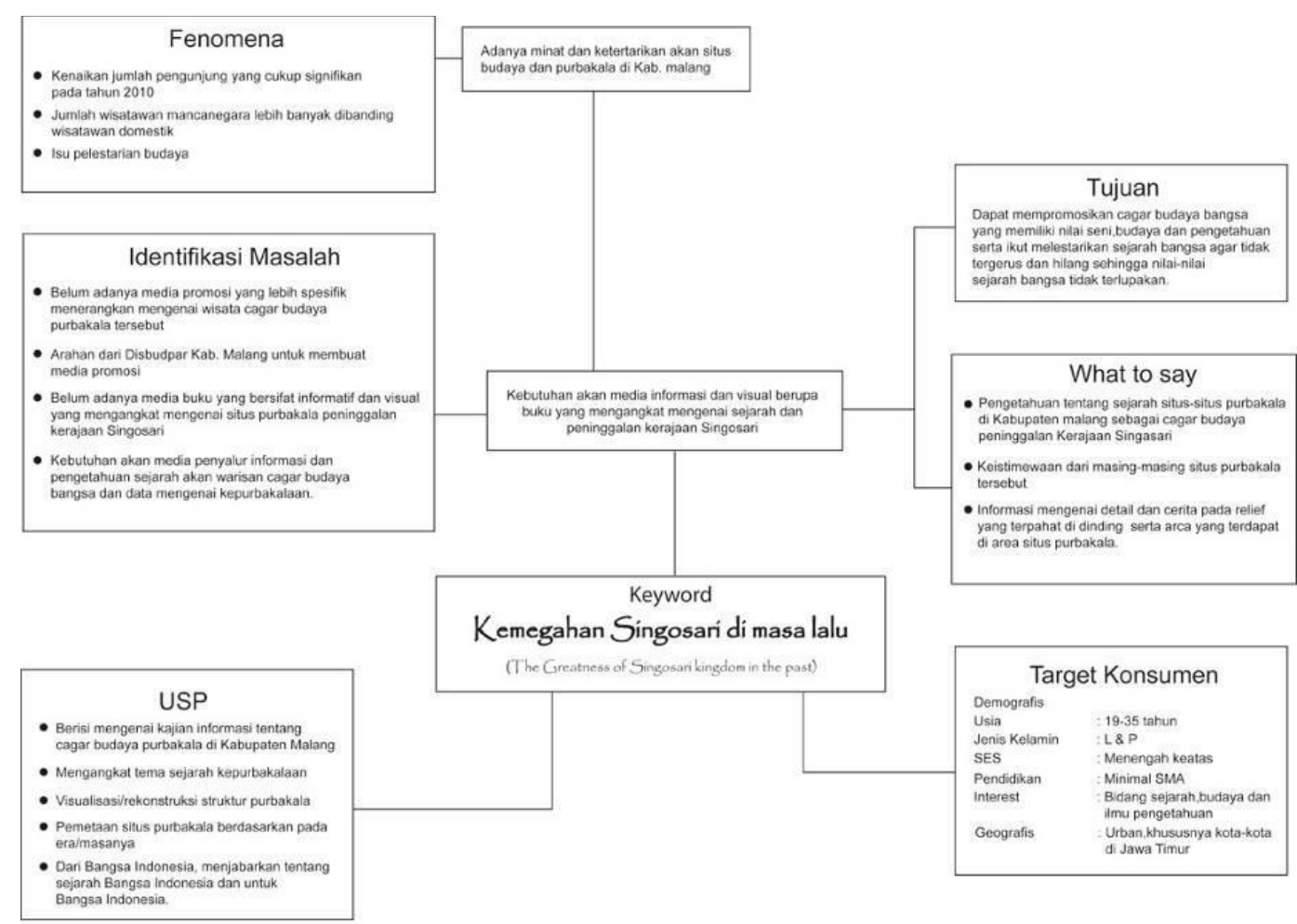

Gambar 2 diagram Keyword

\section{Proses Desain}

Proses desain merupakan tahapan-tahapan dalam merancang buku visual yaitu pengumpulan konten buku seperti pengambilan gambar atau foto dan literatur sejarah, dan rancangan desain layout buku. Proses desain diawali dengan pemilihan alternatif gambar, yang kemudian dilanjutkan dengan pemilihan layout, ilustrasi, font, sistem layout, warna dan system grid.

Alternatif gambar merupakan pilihan variasi gambar yang digunakan dalam layout buku. Berikut merupakan beberapa alternatif gambar dalam layout buku:

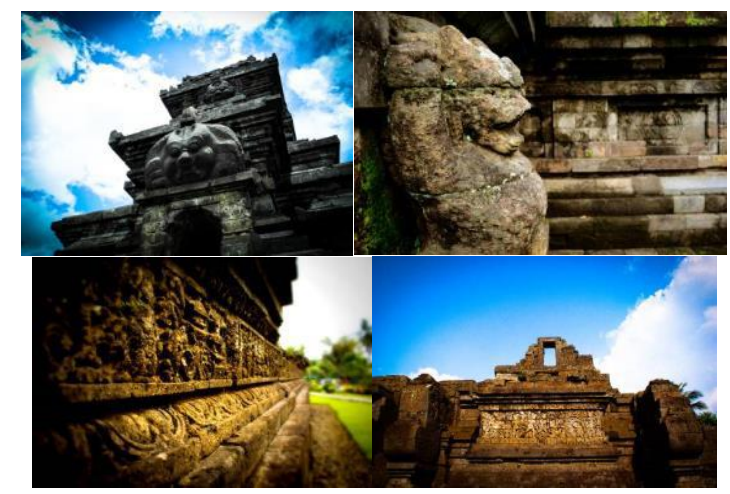

Gambar 3 Alternatif gambar (sumber: Atmaji 2013)

\section{Layout Desain}

Alternatif desain layout berupa sketsa dan desain digital sebagai berikut:

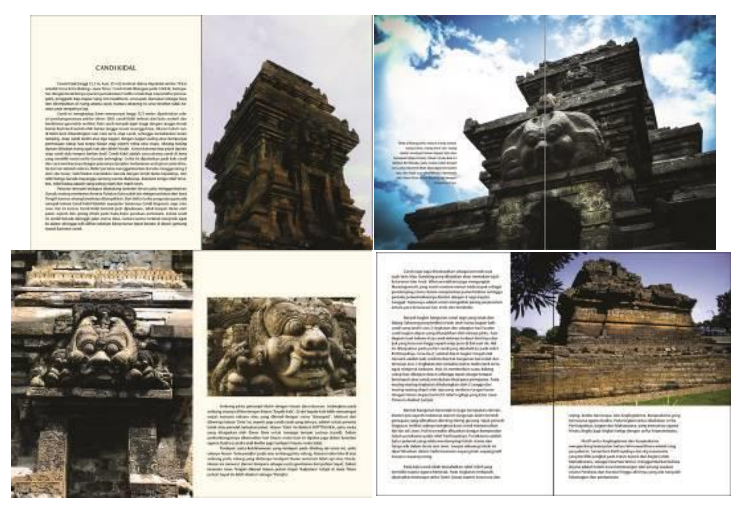

Gambar 4. Alternatif desain layout sketsa dan digital (sumber: Atmaji 2013)

\section{Analisa Ilustrasi}

Ilustrasi yang ditampilkan dalam buku ini nantinya merupakan elemen pendukung isi yang berupa naskah teks. Corak illustrasi yang dipegunakan adalah realis dan vector karena sebagian besar menggambarkan bentukan bangunan candi. 


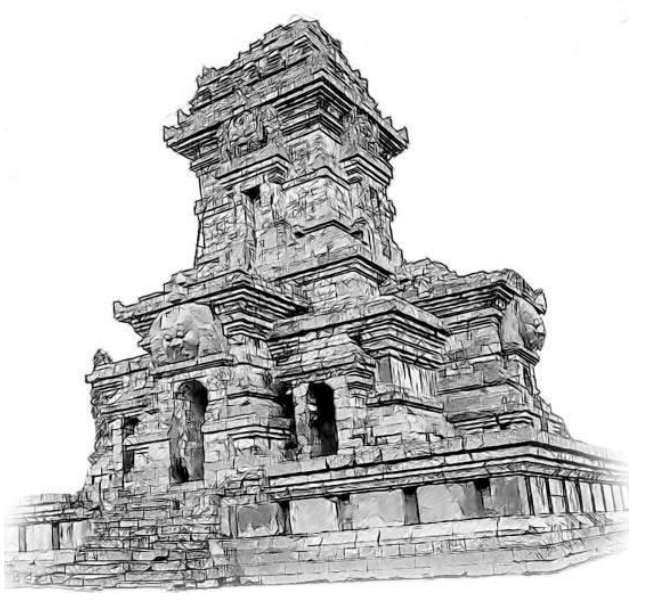

Gambar 5 Ilustrasi Candi (sumber: Atmaji 2013)

3. Sistem Layout

Pada sistem layout, memakai sistem grid modular yang berbasis antara grid kolom namun dibagi oleh banyak struktur baris. Pada heading terdapat ornamen untuk mendukung kesan historical atau masa lalu dan untuk menampilkan kesan eksklusif pada pembabagan per-bab menggunakan warna kuning keemasan dan judul untuk pembabagan juga menggunakan ornamen.

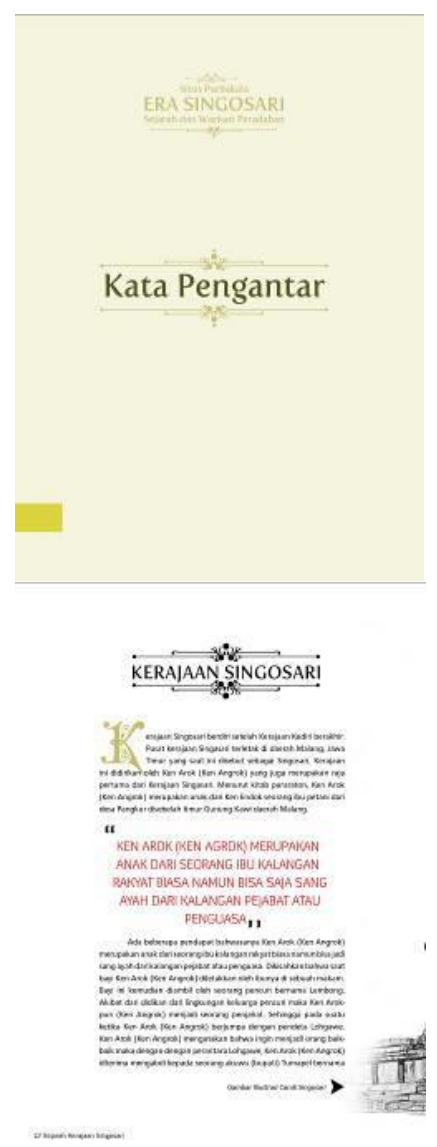

Gambar 6 Desain layout (sumber: Atmaji 2013)

\section{Jenis Font}

Pemilihan huruf menggunakan font yang dapat memberikan kesan formal dan mudah dalam keterbacaannya. Berikut beberapa font yang digunakan:

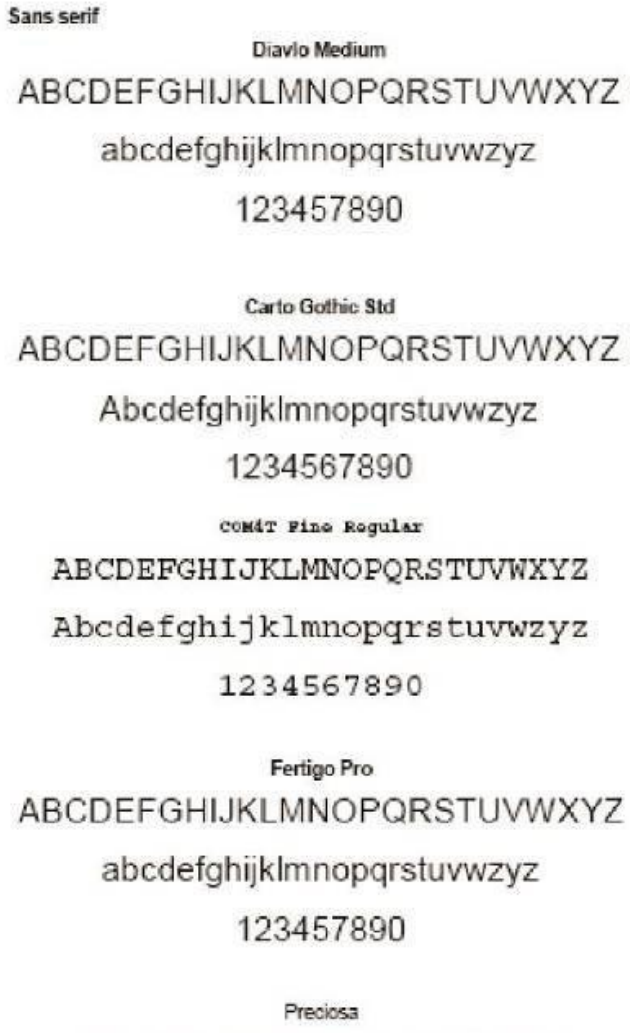

Gambar 7 Jenis Font (sumber: Atmaji 2013)

5. Warna

Warna yang dipergunakan sebagai background pada layout buku adalah hitam-putih dengan mengambil warna dominan dari elemen batu pada situs-situs purbakala.

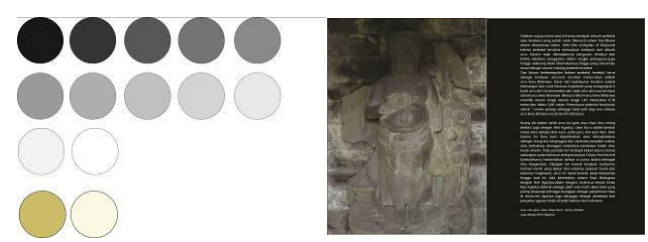

Gambar 8 Tone warna dari warna batu pada situs purbakala dan aplikasi pada media (sumber: Atmaji 2013)

\section{Sistem Grid}

Sistem grid yang dipakai adalah sistem grid modular yang berbasis antara grid kolom namun dibagi oleh banyak struktur baris. 


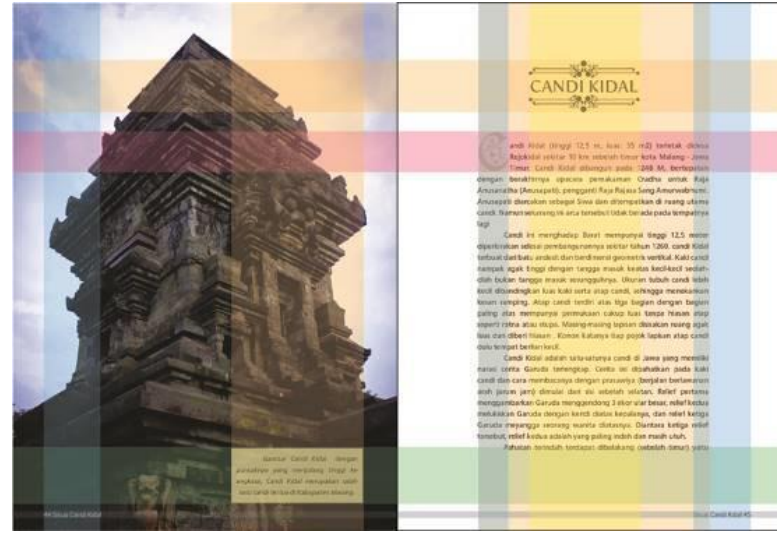

Gambar 9 Sistem grid pada layout buku (sumber: Atmaji 2013)

\section{KESIMPULAN}

Buku Visual Mengenai Cagar Budaya Purbakala Kerajaan Singosari di Kabupaten Malang dibuat untuk menyajikan fakta-fakta menarik seputar peninggalan Kerajaan Singosari yang tersebar di kabupaten Malang. Structural arsitektur dari Bangunan cagar budaya yang ada di Kabupaten Malang menampilkan kemegahan dan kekokohan arsitektural masa lampau yang mampu bertahan ratusan tahun hingga saat ini dan keindahan dari seni pahat pada dinding bangunan serta seni patung pada arca dan bangunan cagar budaya tersebut. . Buku Visual Mengenai Cagar Budaya Purbakala Kerajaan Singosari di Kabupaten Malang diharapkan dapat menjadi media ensiklopedi atau dokumen yang merangkum mengenai peninggalan dari Kerajaan Singosari sehingga bisa dijadikan rujukan bagi akademisi dan penggemar sejarah dalam mencari data mengenai Kerajaan Singosari serta menarik minat dari generasi muda untuk lebih mengenal sejarah bangsa dan negerinya.

\section{DAFTAR PUSTAKA}

Alma, Buchari. (2011). Manajemen Pemasaran dan Pemasaran Jasa edisi revisi. Bandung: indeks.

Ambrose, Gavin and Harris, Paul. (2006). The Fundamentals of Typography: Ava Publishing.

Dinas Kebudayaan dan Pariwisata Provinsi Jawa Timur (2009). Undang-undang Republik Indonesia Tentang Benda Cagar Budaya.

Jean Henry Damais, Soedarmadji. (2012). Majapahit Terracotta. Jakarta: BAB Publishing Indonesia.

Kusrianto, Adi. (2007). Pengantar Desain komunikasi Visual. Yogyakarta: Penerbit Andi.

Rencana Pembangunan Jangka Menengah Daerah Kabupaten malang, 2011-2015, hal. VII-18.

Romansa Italia. (2011, November). National Geographic Traveler.

Samara, Timothy. (2005). Making and Breaking The Grid. USA: Rockport Publisher.

Sumarwan, Ujang. (2002) Perilaku Konsumen: Teori dan Penerapannya dalam Pemasaran. Jakarta: Ghalia Indonesia.

Swann. 1989.How to design grids and use them efectively. Thaidon-Oxford

Widiyanto, M. Balquni. (2011). Perencanaan dan Pengembangan Pariwisata. Bandung. 